\title{
CALCULATION OF WELDING TRUSSES OVERLAP JOINTS MADE OF RECTANGULAR HOLLOW SECTIONS
}

\author{
J. BRÓDKA ${ }^{1}$, M. BRONIEWICZ2
}

\begin{abstract}
The basis for calculating of resistance of welded RHS connections is provided by codes and international guidebooks. In the matter of calculation of the resistance of welded joints, the European standard contains very general recommendations without specifying the detailed calculation procedures, which (the) designers could use in their work. Estimation of resistance of welded semi-rigid joints is a complex issue because it requires determining of effective lengths of welds, their placement on the member walls with their different rigidity, and distribution of components of the load acting on each section of welds in various joint areas. In this paper an approximate assessment is suggested of the resistance of the welded connection in the overlapped $\mathrm{K}$ type joints, made of rectangular hollow sections.
\end{abstract}

Keywords: hollow section structures, trusses joints, RHS brace members, RHS chords, partially overlapped joints, resistance of the welds

\section{INTRODUCTION}

Shaping of overlap trusses joints have been discussed in Polish publications [1], [4] and foreign [6], [7], [10]. The basis for calculating their resistance is provided by the European code EN 1993-1-8 [8] and standardization documents [5], [9]. In the matter of calculation of the resistance of welded joints, the European standard (accepted as the Polish standard) [8] contains a very general recommendations without specifying the detailed calculation procedures, which designers could use in their work. The publication [7] (also the first edition of 1992) contains a rather random information relating only to the joints of T, Y, X, K types formed with gaps between braces. By contrast, in the case of $\mathrm{K}$ type nodes made by partial overlap braces there is no recommendations on how to assess the resistance of welds between the chord and braces.

In 2002 [2] a procedure was developed for approximate evaluation of resistance of welded T, Y, X, K and N gap joints, and in 2007 [3] extended the scope of application of this procedure to such joints made in circular hollow sections.

1 Politechnika Białostocka, Wydział Budownictwa i Inżynierii Środowiska, ul. Wiejska 45 E, 15-351 Białystok

2 Politechnika Białostocka, Wydział Budownictwa i Inżynierii Środowiska, ul. Wiejska 45 E, 15-351 Białystok, mirbron@gmail.com, (Corresponding author). 
The PKN, followed by the European Committee for Standardization (CEN), introduced the EN 1993-1-8 [8] with several minor amendments to remove the errors that occurred to the authors of this standardization document, and a significant change relating to the assessing of the resistance of the connection in the plane of splice between the braces and the chord in the overlapped $\mathrm{K}$ joints. This change, however, still remains formal, because it was forgotten to introduce the calculation procedure.

Fairly simple procedure (although still incomplete) was proposed in the document of Committee XV of International Institute of Welding (IIW) in 2009 [9], presented in detail in [7], [10] and repeated in the draft ISO standard [5].

Here on the bases of cited documents and publications, an approximate assessment is proposed of the resistance of the welded connection in the overlapped $\mathrm{K}$ type joints made of rectangular hollow sections (square), thereby extending the use of the method of calculation presented earlier in [2].

This change in EN 1993-1-8 [8] is following: "The connection of the brace with the surface of the chord is checked on the shear forces in cases where the overlap exceeds $\lambda_{o v, \lim }=60 \%$, and covered splice area of the brace is not welded, or when overlap exceeds $\lambda_{o v, \lim }=80 \%$, and the covered splice area of the brace is welded, or when the braces are made of rectangular hollow sections with dimensions of $h_{i}<b_{i}$ and/or $h_{j}<b_{j}$. The meaning of the symbols will be further specified.

In order to not unduly expand this article, it is referred to methods of assessing the resistance of such joints presented in [1] and [4], and provide only the information necessary to explain the procedure in the calculation of fillet welds. According to EN 1993-1-8 [8]:

a) The overlap ratio is determined as:

$$
\lambda_{o v}=\left(\frac{q}{p}\right) \cdot 100 \%, \text { in } \%
$$

where:

$q$ - length of projected contact area between overlapping brace and chord without presence of the overlapped brace,

$p$ - length of overlap of braces on the chord face.

These dimensions are illustrated in Figure 1a, which implies that $\mathrm{p}=h_{i} / \sin \theta_{i}$ and the value of $q$ should be assessed from the drawing depending on the size of mutual overlap of braces (generally also column and brace) $\left(h_{i}-\right.$ height of the cross-section of the member " $i$ ", $\theta_{i}$ - angle of the member " $i$ ").

b) If the value of negative eccentricity $e>-0,5 h_{0}$, the moment resulting from the eccentricity may be omitted in the calculation of the connection resistance (see Figure 1) ( $h_{0}-$ the height of the chord section in the plane of lattice girder).

c) Where the overlapping brace members have different thicknesses and/or different strength grades, the member with the lowest $t_{t} \cdot f_{y i}$ value should overlap the other member. 
d) Where the overlapping brace members are of different widths, the narrower member should overlap the wider one.

e) In overlap type joints, the overlap should be large enough to ensure that the interconnection of the brace members is sufficient for adequate shear transfer from one brace to the other. In any case the overlap should be at least $25 \%$.

f) The angles $\theta_{i}$ between the chords and the brace members, and between adjacent brace members, should satisfy: $\theta_{i} \geq 30^{\circ}$.

g) The ends of members that meet at a joint should be prepared in such a way that their cross-sectional shape is not modified.

The proposed further procedure for calculating the resistance of the fillet weld may be used at fulfilling the previously mentioned indications.

a)

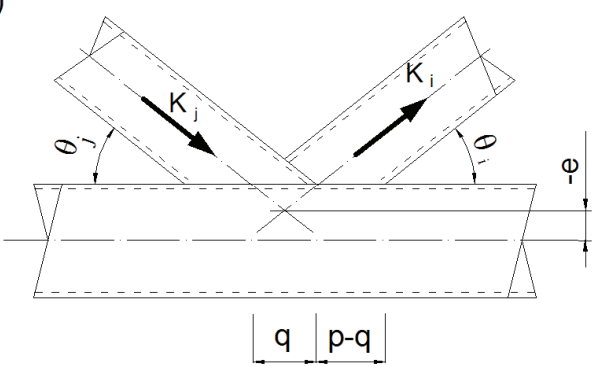

c)

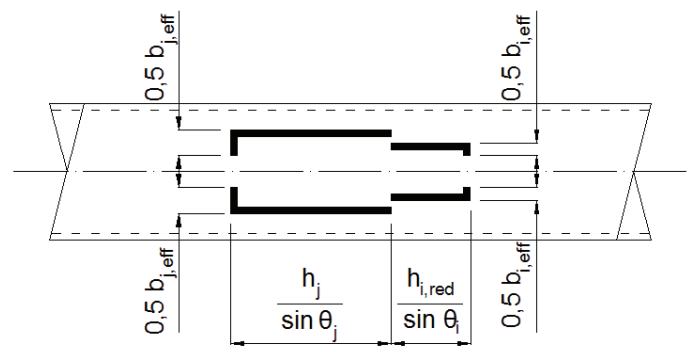

b)

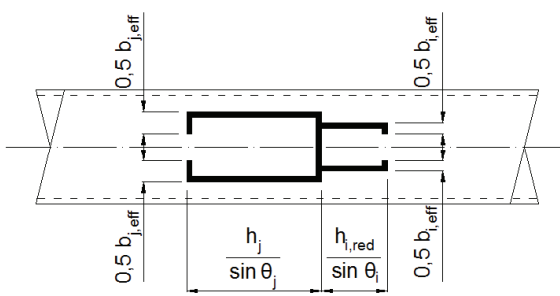

d)

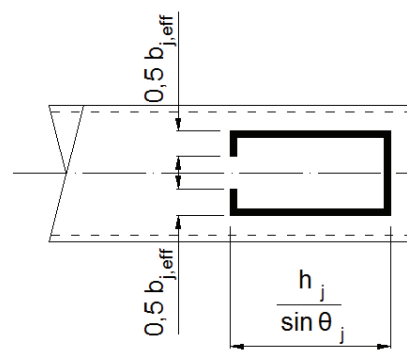

Fig. 1. Dimenstions of joints.

\section{WELD THICKNESS ACCORDING TO EN 1993-1-8}

As indicated by the EN 1993-1-8, [8] welds connecting braces with the chord, must be designed to have sufficient resistance for uneven distributions of stress caused by semirigid joints, and sufficient ability to deformation, allowing redistribution of bending moments.

In welded joints, the connection should normally be formed around the entire perimeter of the hollow section by means of a butt weld, a fillet weld, or combinations 
of the two. However, in partially overlapping joints, the hidden part of the connection need not to be welded, provided that the axial forces in the brace members are such that their components perpendicular to the axis of the chord do not differ by more than $20 \%$.

Estimation of the resistance of welded semi-rigid joints is a complex issue because it requires determining of effective lengths of welds, their placement on the member walls with their different rigidity, and distribution of components of the load acting on each section of welds in various joint areas.

To simplify the evaluation of welds resistance, the design of the resistance of the weld, per unit length of perimeter of a brace member, should not normally be less than the design resistance of the cross-section of that member per unit length of perimeter.

This recommendation is satisfied when full butt welds or fillet welds of such thickness are used that their resistance was equivalent to the capacity of joining members. Methods of assessing the thickness of fillet welds that meet such a requirement is given in [3], [4].

For practical purposes, a maximum thickness of welds is given, depending on the steel grade of the joint members:

- steel S235H: $a_{w}=0,903 t_{1}$,

- steel S275H: $a_{w}=0,986 t_{1}$,

- steel S355H: $a_{w}=1,176 t_{1}$,

- steel S420H: $a_{w}=1,397 t_{1}$,

where:

$a_{w}$ - greatest thickness of fillet weld,

$t_{1}$ - wall thickness of the hollow section.

Presented welds thickness was determined in case of square sections and yield strength $f_{y i} \leq f_{y 0}$ (where $f_{y i}$ - in relation to a brace member, and $f_{y 0}$ - in relation to the chord). In case of rectangular cross sections, the presented values may be slightly different, which is practically not significant.

It should be noted that the standard condition, that the resistance of a weld per unit length of a brace perimeter was generally not less than the brace member capacity, is not always possible to meet. An example of the joint, in which laying only undersize butt weld is possible, the so called flare groove welds, is shown in Figure 7.5 of EN 1993-1-8 [8]. This example indicates a rather rare situation. Much more common is the design of such welds in the corner of the hollow section in splice with a flat element (e.g. plate). The evaluation of the maximum thickness of such welds is given in [3], [4]. It is determined from the relationship:

$a_{w}=0,423 R$ in contact rounding corner with a flat element, $a_{w}=0,735 R$ in contact of two rounding corners,

where:

$R$ - the outer diameter of the corner of hollow section. 
Another example is shown in Figure 2, in which undersize butt welds are used because of the rounded corner of the chord and at various wall thicknesses of joining members.

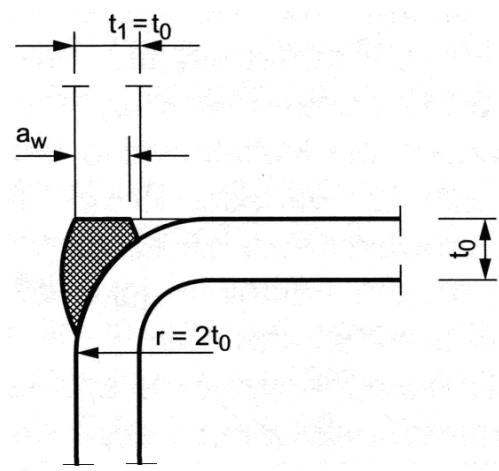

Fig. 2. Rounded corner.

The European standard EN 1993-1-8 [8] also indicates that one can waive the condition requiring the use of full butt weld or the equivalent fillet weld, where a smaller weld size can be justified both with regard to resistance, and with regard to deformation capacity and rotation capacity, taking into account the effective length of the weld.

It must be stated that this situation is most common in the trusses. Typically, crosssections of brace members are selected not because of their capacity, resulting from forces acting on the individual members, but of necessity of:

a) taking into account the resistance of the joint in the presence of its flexibility,

b) taking in assessing of resistance the flexural buckling of compression member,

c) standardization of members only to several sections in case of design tension and compression elements with small longitudinal forces.

Then the design resistance of such members' walls per unit length of a perimeter is always greater than the required capacity of maximally loaded member, in order to meet the condition of the tension safety. These are the situations in which one can apply fillet welds with thickness smaller than it follows from (1).

The IIW recommendations [9] and the draft of ISO standard [5] give a way to evaluate the capacity of the connection in the plane of splice cross-bracings with the chord in the case of $\mathrm{K}$ type joints, where cross-bracings overlap each other partially or completely. Checking the shear of full butt weld (and equivalent fillet weld) is carried out as follows:

- when $\lambda_{o v, \lim }<\lambda_{o v, \lim }<100 \%$, then:

$$
N_{i} \cos \theta_{i}+N_{j} \cos \theta_{j} \leq 0,58 f_{u i} \frac{2 h_{i, r e d}+b_{i, e f f}}{\sin \theta_{i}} t_{i}+0,58 f_{u j} \frac{2 h_{j}+c_{s} b_{j, e f f}}{\sin \theta_{j}} t_{j},
$$


when $\lambda_{o v, \lim }=100 \%$, then:

$$
N_{i} \cos \theta_{i}+N_{j} \cos \theta_{j} \leq 0,58 f_{u i} \frac{2 h_{j}+b_{j}}{\sin \theta_{j}} t_{j},
$$

where:

$N_{i} \quad$ - design axial load in the overlapping brace,

$N_{j} \quad$ - design axial load in the overlapped brace,

$\theta_{i}, \theta_{j} \quad$ - respectively angles of overlapping and overlapped braces in relationship to the chord,

$f_{u i}, f_{u j} \quad$ - respectively tensile strength of overlapping and overlapped braces, provided that $f_{u i} \leq f_{u 0}$ and $f_{u j} \leq f_{u 0}\left(f_{u 0}\right.$-yield strength of the steel used in the chord),

$$
h_{i, \text { red }}=\left(100-\lambda_{\text {ov }}\right) h_{i} / 100 \text {, }
$$

$b_{i}, h_{i} \quad$ - respectively the width and the height of cross section of the overlapping brace,

$b_{j}, h_{j} \quad$ - respectively the width and the height of cross section of the overlapped brace,

$t_{i} \quad-$ wall thickness of the overlapping brace,

$t_{j} \quad-$ wall thickness of the overlapped brace,

$t_{0} \quad-$ wall thickness of the chord,

$b_{0} \quad-$ width of the chord section,

$f_{y 0}, f_{y i}, f_{y j}$ - respectively yield strength of the chord, overlapping and overlapped braces.

$$
\begin{gathered}
b_{i, \text { eff }}=\frac{10}{b_{0} / t_{0}} \cdot \frac{t_{0} f_{y 0}}{t_{i} f_{y i}} b_{i} ; \quad b_{i, e f f} \leq b_{i}, \\
b_{j, \text { eff }}=\frac{10}{b_{0} / t_{0}} \cdot \frac{t_{0} f_{y 0}}{t_{j} f_{y j}} b_{j} ; \quad b_{j, e f f} \leq b_{j} .
\end{gathered}
$$

In case of $\mathrm{K}$ joints hidden seam of brace with chord can be welded or left without welding. This is expressed by the value $\lambda_{o v, \lim }$ and coefficient $c_{s}$. It is assumed:

$c_{s}=1$ and $\lambda_{o v, \text { lim }}=60 \%$ if hidden seam of overlapped brace is not welded, $c_{s}=2$ and $\lambda_{o v, \lim }=80 \%$ if hidden seam of overlapped brace is welded.

Figure 1 indicates the meaning of some of the symbols in the formulas (2.2) and (2.3). These formulas are relationships for checking shear resistance of the welds, which were forgotten in the amendment made by PKN/CEN to Polish standard PN-EN 1993$1-8[8]$. 


\section{Approximate METHODS OF DETERMINING THE CAPACITY OF FILLET WELDS}

Checking of the welded joints of braces with the chord using formulas (2.2) or (2.3) is safe in the case of full butt welds or fillet welds, having a thickness determined in (2.1).

If fillet welds with smaller thickness are designed, it is necessary to check their resistance more accurately, because the conditions imposed by the Eurocode may not be sufficient.

In such design situations, the general equations have to be used, relating to the assessment of capacity of fillet welds, taking in the calculation the effective lengths instead of full lengths around the perimeter.

In Figure 1 examples of applications of the recommendations of IIW [9] and draft ISO standard [5] are shown, and examples of effective lengths of the welds referred to the following situation:

1. All welds are made (also on the hidden length) (Figure 1b).

2. All longitudinal and transverse welds are made without on the hidden length (Figure 1c).

These situations relate to the overlap $25 \%<\lambda_{o v}<80 \%$. In order to simplify the calculation on Figure 1c, the transverse lengths in the place of splice of braces with different widths are not shown. These welds should be made because of hermetic isolation of the interiors of the hollow section members. Figure 1d shows the arrangement of the welds in case of $\lambda_{o v}>100 \%$.

For technical reasons, the K-type joints with the overlapping ratio of $80 \% \approx \lambda_{o v} \leq 100 \%$ should not be used, because in this case the transverse weld on the hidden length is located generally close to the transverse weld of overlapping member, and in the range of $\lambda_{o v} \approx 100 \%$ these two welds mutually overlap. This introduces a very high welding stresses and the thickness of the weld may greatly exceed the values specified as the maximum.

While determining the calculation procedure, it is assumed that the fillet welds around the whole perimeter have the same thickness, despite the possible case that the thicknesses of braces walls are different. Used welds are usually of the same thickness. Welds having the same thickness are most commonly used.

In the analyzed joint, components of the forces in braces parallel to the chord are completely transferred by the welds. However, the component of force perpendicular to the chord is transferred partially from one brace to the other directly via connection between these members, and the remaining value is transferred in their splice with the chord. The arbitrary assumption is made, that the value of the component of force perpendicular to the chord, transferred directly through the welds between the braces (see Figure 1a), is equal:

$$
\begin{gathered}
\Delta K_{i}=\alpha K_{i} \sin \theta_{i}, \text { when } 25 \% \leq \lambda_{o v} \leq 80 \%, \\
\Delta K_{i}=K_{i} \sin \theta_{i}, \text { when } \lambda_{o v}>100 \%,
\end{gathered}
$$


where $\alpha=q / p$ and $0,25 \leq \alpha \leq 0,80$ expressed as the ratio (without specifying the percentage).

Remaining part of the force component perpendicular to the chord is:

$$
\begin{gathered}
\operatorname{red} \Delta K_{j}=K_{j} \sin \theta_{j}-\alpha K_{i} \sin \theta_{i} \text { when } 25 \% \leq \lambda_{o v} \leq 80 \%, \\
\operatorname{red} \Delta K_{j}=K_{j} \sin \theta_{j}-K_{i} \sin \theta_{i}, \text { when } \lambda_{o v}>100 \%,
\end{gathered}
$$

but (3.4) $\operatorname{red} \Delta K_{j}=0$ if the external load is not applied to the joint.

To simplify notation of effective lengths, the throat sections of fillet welds in splice braces with the chord (Figure 3a to c), and throat sections of fillet welds directly between braces (Figure 3d, e) in the cases described previously are shown. The length of these welds is determined as follows:

$l_{1}=h_{j} / \sin \theta_{j} ; \quad l_{2}$ from Eq. (2.6); $l_{3}=h_{i, r e d} / \sin \theta_{i}=(1-\alpha) h_{i} / \sin \theta_{i} ; \quad b_{j, r e d}=b_{j}-2 a_{w} ;$ $l_{4}$ according to Eq. (2.5); $\quad l_{5}=\frac{q}{\left(1+\operatorname{tg} \theta_{j} / \operatorname{tg} \theta_{i}\right) \cos \theta_{j}} ; \quad l_{6}=b_{i} ; \quad l_{7}=h_{i} / \sin \left(\theta_{i}+\theta_{j}\right)$.

a)

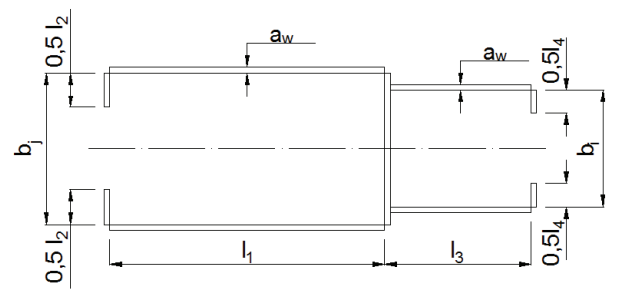

c)

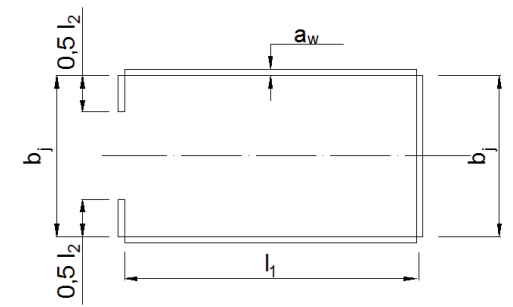

b)

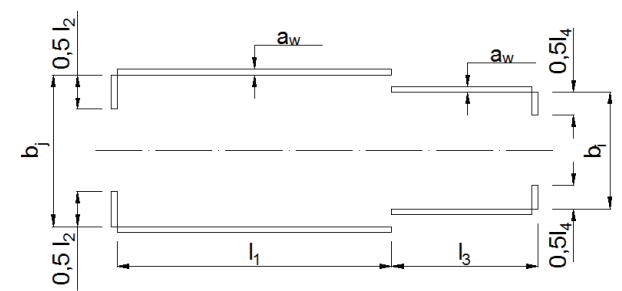

d)

e)

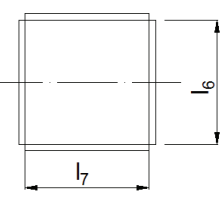

Fig. 3. Dimensions of sections. 
The following design situations are considered:

A. When $25 \% \leq \lambda_{o v} \leq 80 \%$, and in the splice of braces with the chord all welds are arranged (also in hidden part).

The components of the loads in the braces load the throat sections of fillet welds according to Figure 3a. Loads for individual effective lengths are (see Figure 4a):

$$
\begin{gathered}
P_{1}^{\prime}=\left(K_{j} \cos \theta_{j}+K_{i} \cos \theta_{i}\right) l_{1} / \sum l ; \quad P_{2}{ }^{\prime}=\left(K_{j} \cos \theta_{j}+K_{i} \cos \theta_{i}\right) l_{2} / \sum l ; \\
P_{3}{ }^{\prime}=\left(K_{j} \cos \theta_{j}+K_{i} \cos \theta_{i}\right) l_{3} / \sum l ; \quad P_{4}{ }^{\prime}=\left(K_{j} \cos \theta_{j}+K_{i} \cos \theta_{i}\right) l_{4} / \sum l ; \\
P_{b}{ }^{\prime}=\left(K_{j} \cos \theta_{j}+K_{i} \cos \theta_{i}\right) b_{j, \text { red }} / \sum l,
\end{gathered}
$$

where:

$K_{j}, K_{i}$ - design axial loads in overlapped and overlapping braces,

$$
\sum l=2 l_{1}+l_{2}+2 l_{3}+l_{4}+b_{j, r e d} .
$$

The meaning of the other symbols are explained earlier.

The components of the forces in the braces perpendicular to the chord load the throat sections of fillet welds according to Figure $3 \mathrm{a}$. Loads acting on individual effective lengths of welds are (see Figure 4b):

$$
\begin{gathered}
P_{1}^{\prime \prime}=\operatorname{red} \Delta K_{j} l_{1} /\left(2 l_{1}+l_{2}+b_{j, \text { red }}\right) ; \quad P_{2}^{\prime \prime}=\operatorname{red} \Delta K_{j} l_{2} /\left(2 l_{1}+l_{2}+b_{j, \text { red }}\right) ; \\
P_{b}^{\prime \prime}=\operatorname{red} \Delta K_{j} b_{j, \text { red }} /\left(2 l_{1}+l_{2}+b_{j, \text { red }}\right) ; \\
P_{3}^{\prime \prime}=\Delta K_{i} l_{3} /\left(2 l_{3}+l_{4}\right) ; \quad P_{4}^{\prime \prime}=\Delta K_{i} l_{4} /\left(2 l_{3}+l_{4}\right) .
\end{gathered}
$$

Considering the component of the force transmitted directly to the connection between the braces we have:

- values of load parallel to the axis of overlapping brace (Figure 5a):

$$
P_{5}^{\prime}=\Delta K_{i} l_{5} \sin \theta_{j} /\left(2 l_{5}+l_{6}\right) ; \quad P_{6}^{\prime}=\Delta K_{i} l_{6} \sin \theta_{j} /\left(2 l_{5}+l_{6}\right),
$$

- values of load perpendicular to the axis of overlapping brace (Figure $5 b$ ):

$$
P_{5}^{\prime \prime}=\Delta K_{i} l_{5} \cos \theta_{j} /\left(2 l_{5}+l_{6}\right) ; \quad P_{6}^{\prime \prime}=\Delta K_{i} l_{6} \cos \theta_{j} /\left(2 l_{5}+l_{6}\right) .
$$


a)

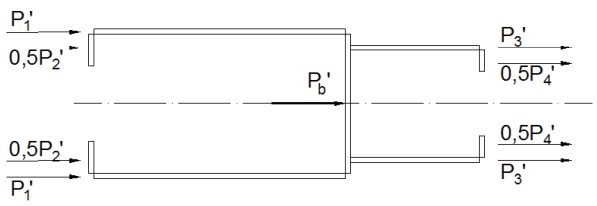

b)

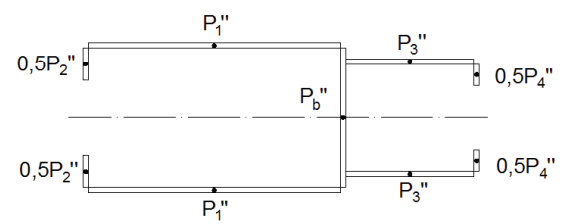

Fig. 4. Loads.

a)

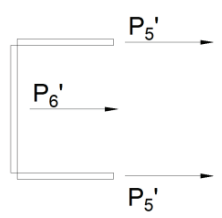

b)

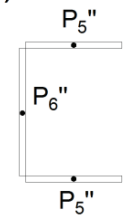

Fig. 5. Loads.

B. When $25 \% \leq \lambda_{o v} \leq 80 \%$ and in the plane of splice braces with the chord not all welds are arranged (without a weld in hidden part). The components of the forces in the braces parallel and perpendicular to the chord load the throat sections of fillet welds shown in Figure 3b. The forces for individual effective lengths of welds can be determined from equation Eq. (3.5), but then $P_{1}^{\prime}, P_{2}{ }^{\prime}, P_{3}^{\prime}$ and $P_{4}^{\prime}$ are calculated including $\sum l=2 l_{1}+l_{2}+2 l_{3}+l_{4}$, and $P_{b}^{\prime}=0$.

Similarly, the loads acting on individual effective lengths of welds parallel to the chord are shown in Figure 4a and loads perpendicular to the chord are shown in Figure $4 \mathrm{~b}$. The forces for individual effective lengths of welds are determined respectively from equation Eq. (3.5) and Eq. (3.6), but with the $b_{j, \text { red }}=0$.

The forces for individual effective lengths of welds in direct connection between the brace members do not change and are determined from the relation Eq. (3.7) and Eq. (3.8).

C. When $\lambda_{o v}=100 \%$, there is a full overlap of braces. The component forces in brace attached to the chord, parallel to its axis, load the welds whose throat sections are shown in Figure 3c. However, the force of the overlapping brace is transmitted directly to overlapped member, through the welds, whose throat sections are shown in Figure 3e.

The contradiction between the information quoted in the literature and the provisions presented in the codes should be explained. The guide CIDECT [7] reported that in the joints with braces, characterized by $25 \% \leq \lambda_{o v} \leq 80 \%$, the effective lengths of welds of overlapping brace can be considered fully effective when carrying loads. 
However, in IIW recommendations [9] and in the draft of ISO standard [5], a more conservative assumption is adopted, as in Figure $3 \mathrm{a}, b$ indicated as $l_{4}=b_{i, \text { eff }}$, rather than $l_{4}=b_{i}$. Moreover, in these publications the direct connection between the braces is not considered at all. In this case, the authors adopted in Figure $3 \mathrm{e}$ the value $l_{6}=b_{i}$.

Forces in welds are determined considering the effective lengths resulting from the Figure $3 \mathrm{c}$ or $3 \mathrm{e}$, according to $\left(\right.$ at $\left.l_{3}=l_{4}=0\right)$ :

$$
\begin{aligned}
& P_{1}^{\prime}, P_{2}^{\prime} \text { and } P_{b}^{\prime} \text { from Eq. (3.5), } \\
& P_{1}^{\prime \prime}, P_{2}^{\prime \prime} \text { and } P_{b}^{\prime \prime} \text { from Eq. (3.6), }
\end{aligned}
$$

When examining the load situation presented at point A, stresses in welds of load parallel to the chord are:

a) on longitudinal lengths (Figure 6a):

- in case of welds placed by the walls of overlapped brace:

$$
\sigma^{\prime}=0 ; \quad \sigma_{\perp}^{\prime}=\tau_{\perp}^{\prime}=0 ; \quad \tau_{I I}^{\prime}=P_{1}^{\prime} /\left(a_{w} \cdot l_{1}\right),
$$

- in case of welds placed by the walls of overlapping brace:

$$
\sigma^{\prime}=0 ; \quad \sigma_{\perp}^{\prime}=\tau_{\perp}^{\prime}=0 ; \quad \tau_{I I}^{\prime}=P_{3}^{\prime} /\left(a_{w} \cdot l_{3}\right),
$$

b) on transverse length not fully cooperating of overlapped brace (Figure 6b):

$$
\sigma^{\prime}=P_{2}^{\prime} /\left(a_{w} l_{2}\right) ; \quad \sigma_{\perp}^{\prime}=\sigma^{\prime} \sin \left(\theta_{j} / 2\right), \quad \tau_{\perp}^{\prime}=\sigma^{\prime} \cos \left(\theta_{j} / 2\right) ; \quad \tau_{I I}^{\prime}=0
$$

c) on transverse length fully cooperating of overlapped brace (Figure 6c):

$$
\sigma^{\prime}=P_{b}^{\prime} /\left(a_{w} b_{j, r e d}\right) ; \quad \sigma_{\perp}^{\prime}=\sigma^{\prime} \cos \left(\theta_{j} / 2\right) ; \quad \tau_{\perp}^{\prime}=\sigma^{\prime} \sin \left(\theta_{j} / 2\right) ; \quad \tau_{I I}^{\prime}=0,
$$

d) on transverse length not fully cooperating of overlapping brace (Figure 6d):

$$
\sigma^{\prime}=P_{4}^{\prime} /\left(a_{w} l_{4}\right) ; \quad \sigma_{\perp}^{\prime}=\sigma^{\prime} \sin \left(\theta_{i} / 2\right) ; \quad \tau_{\perp}^{\prime}=\sigma^{\prime} \cos \left(\theta_{i} / 2\right) ; \quad \tau_{I I}^{\prime}=0
$$


a)

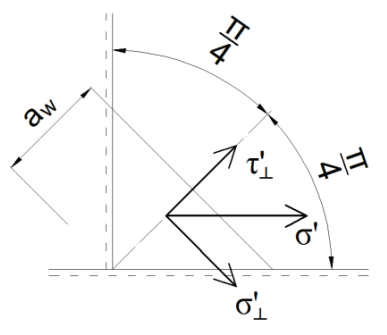

c)

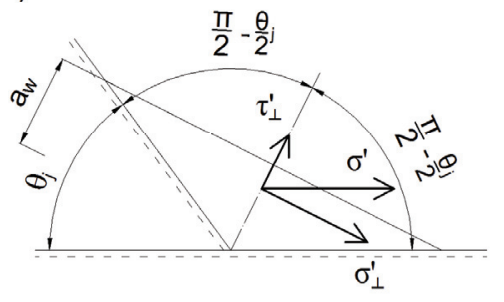

b)

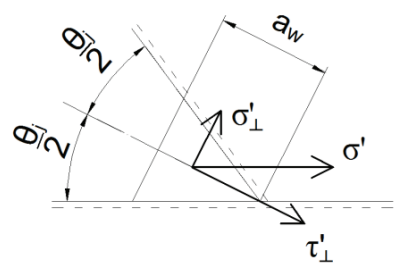

d)

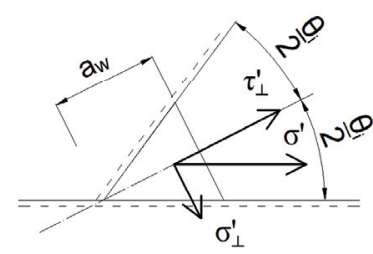

Fig. 6. Stresses.

Considering the loads presented at point A, stresses in the welds from loads perpendicular to the chord are as follows:

a) on longitudinal lengths (Figure 7a):

- in case of welds placed by the walls of overlapped brace:

$$
\sigma^{\prime \prime}=\frac{P_{1}^{\prime \prime}}{a_{w} l_{1}} ; \quad \sigma_{\perp}^{\prime \prime}=\frac{\sigma^{\prime \prime}}{\sqrt{2}} ; \quad \tau_{\perp}^{\prime \prime}=-\frac{\sigma^{\prime \prime}}{\sqrt{2}} ; \quad \tau_{I I}{ }^{\prime \prime}=0,
$$

- in case of welds placed by the walls of overlapping brace:

$$
\sigma^{\prime \prime}=\frac{P_{3}^{\prime \prime}}{a_{w} l_{3}} ; \quad \sigma_{\perp}^{\prime \prime}=-\frac{\sigma^{\prime \prime}}{\sqrt{2}} ; \quad \tau_{\perp}^{\prime \prime}=\frac{\sigma^{\prime \prime}}{\sqrt{2}} ; \quad \tau_{I I}{ }^{\prime \prime}=0,
$$

b) on transverse length not fully cooperating of overlapped brace (Figure 7b):

$$
\sigma^{\prime \prime}=\frac{P_{2}{ }^{\prime \prime}}{a_{w} l_{2}} ; \quad \sigma_{\perp}{ }^{\prime \prime}=-\sigma^{\prime \prime} \cos \frac{\theta_{j}}{2} ; \quad \tau_{\perp}{ }^{\prime \prime}=\sigma^{\prime \prime} \sin \frac{\theta_{j}}{2} ; \quad \tau_{I I}{ }^{\prime \prime}=0,
$$


c) on transverse length fully cooperating of overlapped brace (Figure 7c):

$$
\sigma^{\prime \prime}=\frac{P_{b}^{\prime \prime}}{a_{w} b_{j, r e d}} ; \quad \sigma_{\perp}^{\prime \prime}=\sigma^{\prime \prime} \cos \frac{\theta_{j}}{2} ; \quad \tau_{\perp}^{\prime \prime}=-\sigma^{\prime \prime} \sin \frac{\theta_{j}}{2} ; \quad \tau_{I I}{ }^{\prime \prime}=0
$$

d) on transverse length not fully cooperating of overlapping brace (Figure 7d):

$$
\sigma^{\prime \prime}=\frac{P_{4}^{\prime \prime}}{a_{w} l_{4}} ; \quad \sigma_{\perp}^{\prime \prime}=-\sigma^{\prime \prime} \cos \frac{\theta_{i}}{2} ; \quad \tau_{\perp}^{\prime \prime}=\sigma^{\prime \prime} \sin \frac{\theta_{i}}{2} ; \quad \tau_{I I}{ }^{\prime \prime}=0
$$

a)

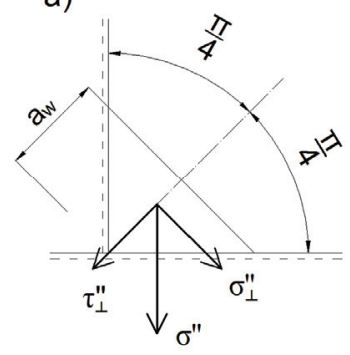

c)

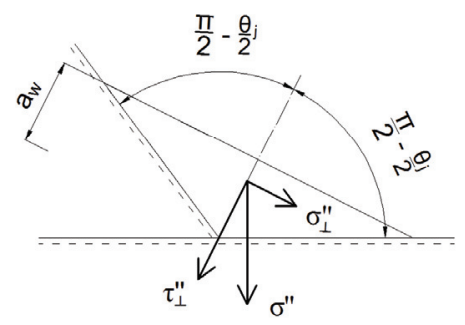

b)

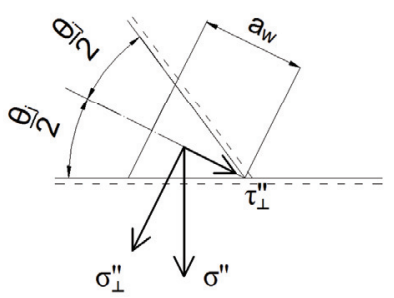

d)

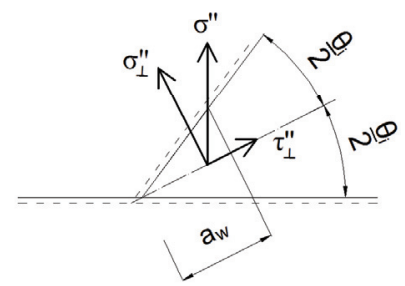

Fig. 7. Stresses.

Considering the loads by point A, stresses in the welds directly made between the brace members parallel to the axis of overlapped brace are:

a) on longitudinal lengths (Figure 8a):

$$
\sigma^{\prime}=0 ; \quad \sigma_{\perp}^{\prime}=\tau_{\perp}^{\prime}=0 ; \quad \tau_{I I}{ }^{\prime}=\frac{P_{5}^{\prime}}{a_{w} l_{5}},
$$


b) on transverse length fully cooperating (Figure $8 b$ ):

$$
\sigma^{\prime}=\frac{P_{6}^{\prime}}{a_{w} l_{6}} ; \quad \sigma_{\perp}^{\prime}=-\sigma^{\prime} \cos \frac{\theta_{i}+\theta_{j}}{2} ; \quad \tau_{\perp}^{\prime}=\sigma^{\prime} \sin \frac{\theta_{i}+\theta_{j}}{2} ; \quad \tau_{I I}{ }^{\prime}=0 .
$$

a)

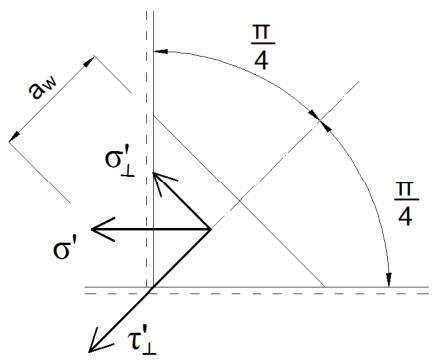

b)

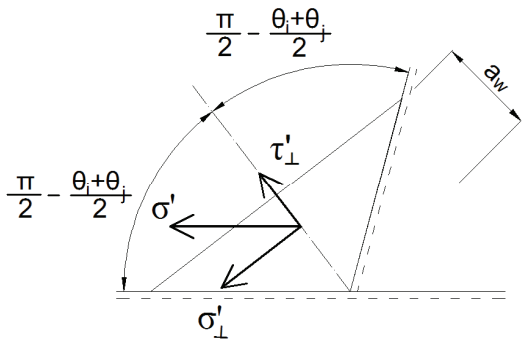

Fig. 8. Stresses.

Considering the loads presented at point A, stresses in the welds directly made between the brace members perpendicular to the axis of overlapped brace are:

a) on longitudinal lengths (Figure 9a):

$$
\sigma^{\prime \prime}=\frac{P_{5}{ }^{\prime \prime}}{a_{w} l_{5}} ; \quad \sigma_{\perp}^{\prime \prime}=-\frac{\sigma^{\prime \prime}}{\sqrt{2}} ; \quad \tau_{\perp}^{\prime \prime}=\frac{\sigma^{\prime \prime}}{\sqrt{2}} ; \quad \tau_{I I}^{\prime \prime}=0,
$$

b) on transverse length fully cooperating (Figure 9b):

$$
\sigma^{\prime \prime}=\frac{P_{6}^{\prime \prime}}{a_{w} l_{6}} ; \quad \sigma_{\perp}^{\prime \prime}=\sigma^{\prime \prime} \cos \frac{\theta_{j}+\theta_{i}}{2} ; \quad \tau_{\perp}^{\prime \prime}=-\sigma^{\prime \prime} \sin \frac{\theta_{j}+\theta_{i}}{2} ; \quad \tau_{I I}{ }^{\prime \prime}=0 .
$$

a)

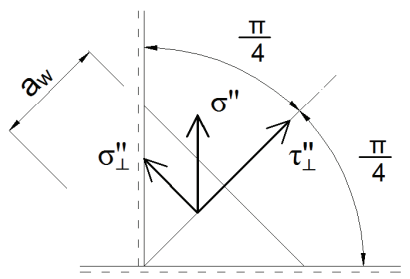

b)

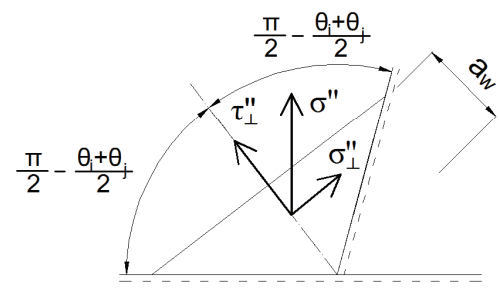

Fig. 9. Stresses. 
Component of the stresses on the individual lengths of welds should be added together, taking the values of forces in the braces after transforming them into components parallel or perpendicular to the axis of the chord, or parallel or perpendicular to the axis of the overlapped brace, considering following relations:

$$
\tau_{I I}=\tau_{I I}^{\prime}+\tau_{I I}^{\prime \prime} ; \quad \sigma_{\perp}=\sigma_{\perp}^{\prime}+\sigma_{\perp}^{\prime \prime} ; \quad \tau_{\perp}=\tau_{\perp}^{\prime}+\tau_{\perp}^{\prime \prime}
$$

Having determined the added components, we can assess the safety of the transverse and longitudinal welds (fully or partially cooperating), using standardized formulas [8]:

$$
\left|\sigma_{\perp}^{2}+3\left(\tau_{\perp}^{2}+\tau_{I I}^{2}\right)\right| \leq f_{u} /\left(\beta_{w} \gamma_{M 2}\right),
$$

$$
\sigma_{\perp} \leq 0,9 f_{u} / \gamma_{M 2}
$$

where:

$\beta_{w}$ - is the correlation factor of fillet welds,

$f_{u}$ - is the nominal ultimate tensile strength of steel,

$\gamma_{M 2}=1,25$ is the safety factor.

Similarly, we have to proceed in the case of loads analyzed in relation to the design case $\mathrm{B}$, keeping in mind that the transverse weld at hidden place is not performed.

In the case of design $\mathrm{C}$, the calculation is greatly reduced. The checking procedure is analogous. We should also check stresses in the transverse weld, located near the connection of overlapped brace with the chord (Figure 10). We can use the loads from Eq. (3.9) and (3.10). Considering this situation, the stress components are:

a) on transverse length from the load parallel to the axis of overlapped brace (Figure 10a):

$$
\sigma^{\prime}=\frac{P_{6}^{\prime}}{a_{w} l_{6}} ; \quad \sigma_{\perp}^{\prime}=-\sigma^{\prime} \sin \frac{\theta_{j}+\theta_{i}}{2} ; \quad \tau_{\perp}^{\prime}=-\sigma^{\prime} \cos \frac{\theta_{j}+\theta_{i}}{2} ; \quad \tau_{I I}{ }^{\prime}=0 .
$$

b) on transverse length from the load perpendicular to the axis of overlapped brace (Figure 10b):

$$
\sigma^{\prime \prime}=\frac{P_{6}^{\prime \prime}}{a_{w} l_{6}} ; \quad \sigma_{\perp}^{\prime \prime}=-\sigma^{\prime \prime} \cos \frac{\theta_{j}+\theta_{i}}{2} ; \quad \tau_{\perp}^{\prime \prime}=\sigma^{\prime \prime} \sin \frac{\theta_{j}+\theta_{i}}{2} ; \quad \tau_{I I}^{\prime \prime}=0 .
$$




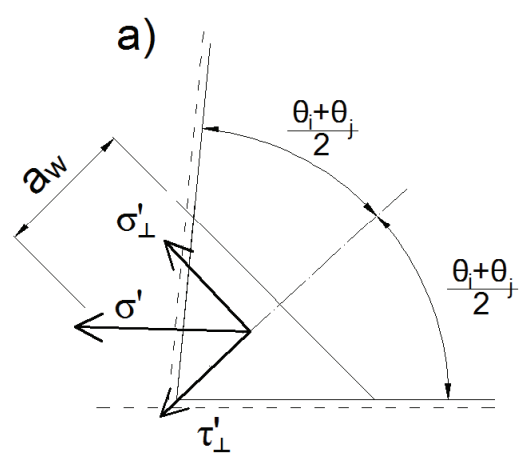

b)

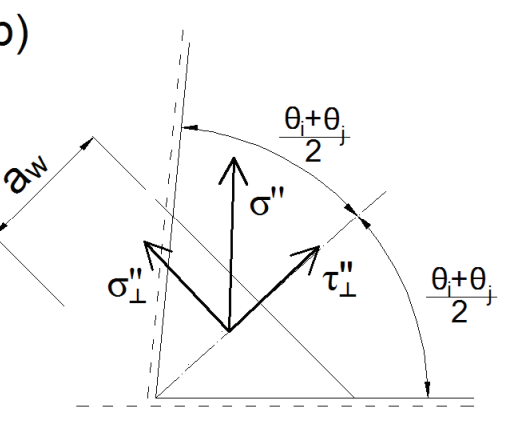

Fig. 10. Stresses.

\section{Design example}

Checking the resistance of welds of compression member of uniplanar truss made of hot rolled rectangular hollow section is considered [11] (Figure 11). Assuming the steel grade of S355H $f_{y}=355 \mathrm{~N} / \mathrm{mm}^{2}, f_{u}=490 \mathrm{~N} / \mathrm{mm}^{2}$ (the thickness $t \leq 40$ $\mathrm{mm}$ ), chord: $h_{0}=120 \mathrm{~mm}, b_{0}=100 \mathrm{~mm}, t_{0}=6 \mathrm{~mm}, A_{0}=24,0 \mathrm{~cm}^{2}, N_{0}=-159,9 \mathrm{kN}$, compressed brace: $h_{2}=80 \mathrm{~mm}, b_{2}=60 \mathrm{~mm}, t_{2}=4 \mathrm{~mm} ; N_{2 . E d}=-136,1 \mathrm{kN}$, tension brace: $h_{1}=60 \mathrm{~mm}, b_{1}=40 \mathrm{~mm}, t_{1}=3,2 \mathrm{~mm}, N_{1 . E d}=+103,2 \mathrm{kN}$, the angle between the chord and the tension brace is $\theta_{1}=50,34^{\circ}>30^{\circ}$, while the angle between the chord and the compression brace $\theta_{2}=40,02^{\circ}>30^{\circ}$, the joint of type $\mathrm{K}$ with the overlap between braces is selected. Overlapped part of the splice is not welded.

1. Determining of overlap value

Assuming $e=-34 \mathrm{~mm}$. Hence the overlap is:

$$
\begin{aligned}
& q=\left(e+\frac{h_{0}}{2}\right) \frac{\sin \left(\theta_{1}+\theta_{2}\right)}{\sin \theta_{1} \sin \theta_{2}}-\frac{h_{1}}{2 \sin \theta_{1}}-\frac{h_{2}}{2 \sin \theta_{2}}= \\
& =\left(-34+\frac{120}{2}\right) \frac{1,0}{0,7698 \cdot 0,6431}-\frac{60}{2 \cdot 0,7698}-\frac{80}{2 \cdot 0,6431}=-48,65 \mathrm{~mm}, \\
& p=h_{1} / \sin \theta_{1}=60 / 0,7698=77,9 \mathrm{~mm}, \\
& \lambda_{o v}=(q / p) \cdot 100 \%=(48,65 / 77,9) \cdot 100 \%=62,4 \% .
\end{aligned}
$$




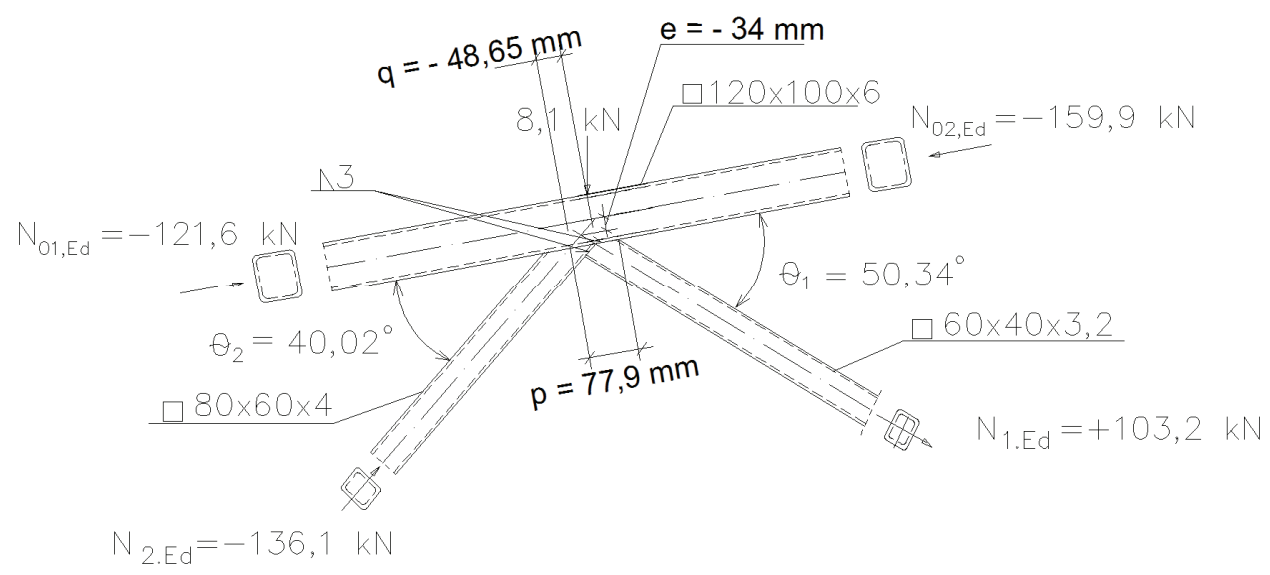

Fig. 11. Design example.

2. Verification of the design conditions : $25 \%<\lambda_{o v}=62,4 \%<100 \%$.

$$
\begin{aligned}
& \beta_{1}=\frac{b_{1}}{b_{0}}=\frac{40}{100}=0,4>0,25, \beta_{2}=\frac{b_{2}}{b_{0}}=\frac{60}{100}=0,6>0,25, \\
& \lambda_{1 h}=\frac{h_{1}}{t_{1}}=\frac{60}{3,2}=18,8<35, \quad \lambda_{1 b}=\frac{b_{1}}{t_{1}}=\frac{40}{3,2}=12,5<35, \\
& 0,5<\frac{h_{0}}{b_{0}}=\frac{120}{100}=1,2<2,0,5<\frac{h_{1}}{b_{1}}=\frac{60}{40}=1,5<2, \frac{b_{1}}{b_{2}}=\frac{40}{60}=0,67<0,75 .
\end{aligned}
$$

3. Determining the strength of joint

$$
\begin{aligned}
& b_{e f f}=\frac{10}{b_{0} / t_{0}} \frac{f_{y 0} t_{0}}{f_{y i} t_{i}} b_{i}=\frac{10}{100 / 6} \frac{355 \cdot 6}{355 \cdot 3,2} \cdot 40=45 \mathrm{~mm}>b_{i}=40 \mathrm{~mm} . \\
& b_{e, o v}=\frac{10}{b_{j} / t_{j}} \frac{f_{y j} t_{j}}{f_{i} t_{i}} b_{i}=\frac{10}{60 / 4} \frac{355 \cdot 4}{355 \cdot 3,2} \cdot 40=33,3 \mathrm{~mm} . \\
& N_{1, R d}=f_{y 1} t_{1}\left(b_{e f f}+b_{e, o v}+2 h_{1}-4 t_{1}\right) / \gamma_{M 5}=355 \cdot 3,2(40+33,3+2 \cdot 60-4 \cdot 3,2) / 1,0= \\
& =205048 \mathrm{~N}=205,0 \mathrm{kN}, \\
& N_{2, R d}=N_{1, R d} \frac{\sin \theta_{1}}{\sin \theta_{2}}=205,0 \cdot \frac{0,7698}{0,6431}=245,4 \mathrm{kN} .
\end{aligned}
$$


Checking the strength of joint

$$
\begin{aligned}
& \frac{103,2}{205,0}=0,50<1,0, \\
& \frac{136,1}{245,4}=0,55<1,0 .
\end{aligned}
$$

Checking the strength of joint according to plastic failure of the chord

$$
\begin{aligned}
& M_{0}= \pm 0,5\left(N_{02, E d} \cdot-N_{01, E d}\right) e= \pm 0,5(-159,9+121,6) \cdot 34= \pm 651,1 \mathrm{kNmm}, \\
& M_{0, p l}=W_{p l, 0} \cdot f_{y} / \gamma_{M 1}=97,9 \cdot 10^{3} \cdot 355 / 1,0=347,5 \cdot 10^{2} \mathrm{kNmm}, \\
& N_{0, p l}=A_{0} \cdot f_{y} / \gamma_{M 1}=24,0 \cdot 10^{2} \cdot 355 / 1,0=852 \cdot 10^{3} \mathrm{~N}=852 \mathrm{kN}, \\
& \frac{N_{0}}{N_{0, p l}}+\frac{M_{0}}{M_{0 . p l}}=\frac{159,9}{852,0}+\frac{651,1}{34750}=0,21<1,0
\end{aligned}
$$

4. Checking the shear resistance of fillet welds with thicknesses equal according to their resistance butt welds

Determining the thickness of the weld

$$
\begin{aligned}
& a_{w 1}=1,176 t_{1}=1,176 \cdot 3,2=3,8 \mathrm{~mm}, \\
& a_{w 2}=1,176 t_{2}=1,176 \cdot 4=4,7 \mathrm{~mm} .
\end{aligned}
$$

Determining the effective lengths of welds (Eq. (2.5) and (2.6))

$$
\begin{aligned}
& h_{i, \text { red }}=\left(100-\lambda_{o v}\right) h_{i} / 100=(100-62,4) 60 / 100=22,6 \mathrm{~mm}, \\
& b_{i, e f f}=\frac{10}{b_{0} / t_{0}} \frac{f_{y 0} t_{0}}{f_{y i} t_{i}} b_{i}=\frac{10}{100 / 6} \frac{355 \cdot 6}{355 \cdot 3,2} \cdot 40=45 \mathrm{~mm}>b_{i}=40 \mathrm{~mm}, \\
& b_{j, \text { eff }}=\frac{10}{b_{0} / t_{0}} \frac{f_{y 0} t_{0}}{f_{y j} t_{j}} b_{j}=\frac{10}{100 / 6} \frac{355 \cdot 6}{355 \cdot 4} \cdot 60=54,0 \mathrm{~mm}<b_{j}=60 \mathrm{~mm} .
\end{aligned}
$$

Shear resistance of the welds (Eq. (2.2)) 


$$
\begin{aligned}
& N_{1} \cos \theta_{1}+N_{2} \cos \theta_{2}=103,2 \cdot 0,6382+136,1 \cdot 0,7658=170,1 \mathrm{kN}< \\
& 0,58 f_{u i} \frac{2 h_{i, r e d}+b_{i, e f f}}{\sin \theta_{i}} t_{i}+0,58 f_{u j} \frac{2 h_{j}+c_{s} b_{j, e f f}}{\sin \theta_{j}} t_{j}= \\
& =0,58 \cdot 490 \cdot \frac{2 \cdot 22,6+40}{0,7698} \cdot 3,2+0,58 \cdot 490 \cdot \frac{2 \cdot 80+1 \cdot 54}{0,6431} \cdot 4=478940 \mathrm{~N}=478,9 \mathrm{kN} .
\end{aligned}
$$

Conclusion: The shear resistance of thick fillet welds is sufficient.

5. Checking the shear resistance of the small thickness fillet weld Assumed thickness of welds $a_{w}=3,0 \mathrm{~mm}$.

a) Determining of lengths of each welds:

$$
\begin{aligned}
& \alpha=q / p=0,624, \\
& l_{1}=h_{2} / \sin \theta_{2}=80 / 0,6431=124,4 \mathrm{~mm}, \\
& l_{2}=b_{j, e f f}=54 \mathrm{~mm}, \\
& l_{3}=(1-\alpha) h_{1} / \sin \theta_{1}=(1-0,624) 60 / 0,7698=29,3 \mathrm{~mm}, \\
& l_{4}=b_{i, e f f}=40 \mathrm{~mm}, \\
& l_{5}=\frac{q}{\left(1+\tan \theta_{2} / \tan \theta_{1}\right) \cos \theta_{2}}=\frac{48,65}{(1+0,8397 / 1,2062) 0,7658}=37,5 \mathrm{~mm}, \\
& l_{6}=b_{1}=40 \mathrm{~mm}, \\
& \sum l=2 \cdot l_{1}+l_{2}+2 l_{3}+l_{4}=2 \cdot 124,4+54+2 \cdot 29,3+40=401,4 \mathrm{~mm} .
\end{aligned}
$$

b) Calculating of loads in effective lengths of welds:

$$
\begin{aligned}
& \Delta K_{1}=\alpha K_{1} \sin \theta_{1}=0,624 \cdot 103,2 \cdot 0,7698=49,6 \mathrm{kN}, \\
& \operatorname{red} \Delta K_{2}=K_{2} \sin \theta_{2}-\alpha K_{1} \sin \theta_{1}=136,1 \cdot 0,6431-0,624 \cdot 103,2 \cdot 0,7698=38,0 \mathrm{kN}, \\
& P_{1}^{\prime}=\left(K_{2} \cos \theta_{2}+K_{1} \cos \theta_{1}\right) l_{1} / \sum l=(136,1 \cdot 0,7658+103,2 \cdot 0,6382) 124,4 / 401,4= \\
& =52,7 \mathrm{kN},
\end{aligned}
$$




$$
\begin{aligned}
& P_{1}^{\prime \prime}=\operatorname{red} \Delta K_{2} \cdot l_{1} /\left(2 l_{1}+l_{2}\right)=38,0 \cdot 124,4 /(2 \cdot 124,4+54)=15,6 \mathrm{kN}, \\
& P_{2}^{\prime}=\left(K_{2} \cos \theta_{2}+K_{1} \cos \theta_{1}\right) l_{2} / \sum l=(136,1 \cdot 0,7658+103,2 \cdot 0,6382) 54 / 401,4= \\
& =22,9 \mathrm{kN}, \\
& P_{2}^{\prime \prime}=\operatorname{red} \Delta K_{2} \cdot l_{2} /\left(2 l_{1}+l_{2}\right)=38,0 \cdot 54 /(2 \cdot 124,4+54)=6,8 \mathrm{kN}, \\
& P_{3}^{\prime}=\left(K_{2} \cos \theta_{2}+K_{1} \cos \theta_{1}\right) l_{3} / \sum l=(136,1 \cdot 0,7658+103,2 \cdot 0,6382) 29,3 / 401,4= \\
& =12,4 \mathrm{kN}, \\
& P_{3}^{\prime \prime}=\Delta K_{1} \cdot l_{3} /\left(2 l_{3}+l_{4}\right)=49,6 \cdot 29,3 /(2 \cdot 29,3+40)=14,7 \mathrm{kN}, \\
& P_{4}^{\prime}=\left(K_{2} \cos \theta_{2}+K_{1} \cos \theta_{1}\right) l_{4} / \sum l=(136,1 \cdot 0,7658+103,2 \cdot 0,6382) 40 / 401,4= \\
& =16,9 \mathrm{kN}, \\
& P_{4}^{\prime \prime}=\Delta K_{1} \cdot l_{4} /\left(2 l_{3}+l_{4}\right)=49,6 \cdot 40,0 /(2 \cdot 29,3+40)=20,1 \mathrm{kN}, \\
& P_{5}^{\prime}=\Delta K_{1} \cdot \sin \theta_{2} l_{5} /\left(2 l_{5}+l_{6}\right)=49,6 \cdot 0,6431 \cdot 37,5 /(2 \cdot 37,5+40)=10,4 \mathrm{kN}, \\
& P_{5}^{\prime \prime}=\Delta K_{1} \cdot \cos \theta_{2} l_{5} /\left(2 l_{5}+l_{6}\right)=40,6 \cdot 0,7658 \cdot 37,5 /(2 \cdot 37,5+40)=10,1 \mathrm{kN}, \\
& P_{6}^{\prime}=\Delta K_{1} \cdot \sin \theta_{2} l_{6} /\left(2 l_{5}+l_{6}\right)=40,6 \cdot 0,6431 \cdot 40 /(2 \cdot 37,5+40)=9,1 \mathrm{kN}, \\
& P_{6}^{\prime \prime}=\Delta K_{1} \cdot \cos \theta_{2} l_{6} /\left(2 l_{5}+l_{6}\right)=40,6 \cdot 0,7658 \cdot 40 /(2 \cdot 37,5+40)=10,8 \mathrm{kN} .
\end{aligned}
$$

c) Stresses in welds of load parallel to the chord:

- longitudinal welds placed by the walls of overlapped brace in connection with the chord - Eq. (3.11):

$$
\begin{aligned}
& \sigma^{\prime}=0, \\
& \sigma_{\perp}^{\prime}=\tau_{\perp}^{\prime}=0, \\
& \tau_{I I}^{\prime}=\frac{P_{1}^{\prime}}{a_{w} l_{1}}=\frac{52,7 \cdot 10^{3}}{3,0 \cdot 124,4}=141,2 \mathrm{MPa},
\end{aligned}
$$

- transversal weld placed by the not fully cooperating wall of overlapped brace in connection with the chord - Eq. (3.13): 


$$
\begin{aligned}
& \sigma^{\prime}=\frac{P_{2}^{\prime}}{a_{w} l_{2}}=\frac{22,9 \cdot 10^{3}}{3,0 \cdot 54}=141,4 \mathrm{MPa}, \\
& \sigma_{\perp}^{\prime}=\sigma^{\prime} \sin \frac{\theta_{2}}{2}=141,4 \cdot 0,3422=48,4 \mathrm{MPa}, \\
& \tau_{\perp}^{\prime}=\sigma^{\prime} \cos \frac{\theta_{2}}{2}=141,1 \cdot 0,9396=132,6 \mathrm{MPa}, \\
& \tau_{I I}^{\prime}=0,
\end{aligned}
$$

- longitudinal welds placed by the walls of overlapping brace in connection with the chord - Eq. (3.12):

$$
\begin{aligned}
& \sigma^{\prime}=0 \\
& \sigma_{\perp}^{\prime}=\tau_{\perp}^{\prime}=0 \\
& \tau_{I I}^{\prime}=\frac{P_{3}^{\prime}}{a_{w} l_{3}}=\frac{12,4 \cdot 10^{3}}{3,0 \cdot 29,3}=141,1 \mathrm{MPa},
\end{aligned}
$$

- transversal weld placed by the not fully cooperating wall of overlapping brace in connection with the chord - Eq. (3.15):

$$
\begin{aligned}
& \sigma^{\prime}=\frac{P_{4}^{\prime}}{a_{w} l_{4}}=\frac{16,9 \cdot 10^{3}}{3,0 \cdot 40}=140,8 \mathrm{MPa}, \\
& \sigma_{\perp}^{\prime}=\sigma^{\prime} \sin \frac{\theta_{1}}{2}=140,8 \cdot 0,4253=59,9 \mathrm{MPa}, \\
& \tau_{\perp}^{\prime}=\sigma^{\prime} \cos \frac{\theta_{1}}{2}=140,8 \cdot 0,9050=127,4 \mathrm{MPa}, \\
& \tau_{I I}^{\prime}=0,
\end{aligned}
$$

- longitudinal welds placed by the walls of overlapping brace in connection with the overlapped brace - Eq. (3.21):

$$
\sigma^{\prime}=0 \text {, }
$$




$$
\begin{aligned}
& \sigma_{\perp}^{\prime}=\tau_{\perp}^{\prime}=0, \\
& \tau_{I I}^{\prime}=\frac{P_{5}^{\prime}}{a_{w} l_{5}}=\frac{10,4 \cdot 10^{3}}{3,0 \cdot 37,5}=92,4 \mathrm{MPa},
\end{aligned}
$$

- transversal weld placed by the wall of overlapping brace in connection with the overlapped brace (near the connection of overlapped brace with the chord) - Eq. (3.22):

$$
\begin{aligned}
& \sigma^{\prime}=\frac{P_{6}^{\prime}}{a_{w} l_{6}}=\frac{9,1 \cdot 10^{3}}{3,0 \cdot 40}=75,8 \mathrm{MPa}, \\
& \sigma_{\perp}^{\prime}=-\sigma^{\prime} \cos \frac{\theta_{1}+\theta_{2}}{2}=-75,8 \cdot 0,7049=-53,4 \mathrm{MPa}, \\
& \tau_{\perp}^{\prime}=\sigma^{\prime} \sin \frac{\theta_{1}+\theta_{2}}{2}=75,8 \cdot 0,7093=53,8 \mathrm{MPa}, \\
& \tau_{I I}^{\prime}=0 .
\end{aligned}
$$

d) Stresses in welds of load perpendicular to the chord

- longitudinal welds placed by the walls of overlapped brace in connection with the chord - Eq. (3.16):

$$
\begin{aligned}
& \sigma^{\prime \prime}=\frac{P_{1}^{\prime \prime}}{a_{w} l_{1}}=\frac{15,6 \cdot 10^{3}}{3 \cdot 124,4}=41,8 \mathrm{MPa}, \\
& \sigma_{\perp}^{\prime \prime}=\frac{\sigma^{\prime \prime}}{\sqrt{2}}=\frac{41,8}{\sqrt{2}}=29,6 \mathrm{MPa}, \\
& \tau_{\perp}^{\prime \prime}=-\frac{\sigma^{\prime \prime}}{\sqrt{2}}=-\frac{41,8}{\sqrt{2}}=-29,6 \mathrm{MPa}, \\
& \tau_{I I}^{\prime \prime}=0
\end{aligned}
$$

- transversal weld placed by the not fully cooperating wall of overlapped brace in connection with the chord - Eq. (3.18): 


$$
\begin{aligned}
& \sigma^{\prime \prime}=\frac{P_{2}^{\prime \prime}}{a_{w} l_{2}}=\frac{6,8 \cdot 10^{3}}{3,0 \cdot 54,0}=42,0 \mathrm{MPa}, \\
& \sigma_{\perp}^{\prime \prime}=-\sigma^{\prime \prime} \cos \frac{\theta_{2}}{2}=-42,0 \cdot 0,9396=-39,5 \mathrm{MPa}, \\
& \tau_{\perp}^{\prime \prime}=\sigma^{\prime \prime} \sin \frac{\theta_{2}}{2}=42,0 \cdot 0,3422=14,4 \mathrm{MPa}, \\
& \tau_{I I}^{\prime \prime}=0
\end{aligned}
$$

- longitudinal welds placed by the walls of overlapping brace in connection with the chord - Eq. (3.17):

$$
\begin{aligned}
& \sigma^{\prime \prime}=\frac{P_{3}^{\prime \prime}}{a_{w} l_{3}}=\frac{14,7 \cdot 10^{3}}{3 \cdot 29,3}=167,2 \mathrm{MPa}, \\
& \sigma_{\perp}^{\prime \prime}=-\frac{\sigma^{\prime \prime}}{\sqrt{2}}=-\frac{167,2}{\sqrt{2}}=-118,2 \mathrm{MPa}, \\
& \tau_{\perp}^{\prime \prime}=\frac{\sigma^{\prime \prime}}{\sqrt{2}}=\frac{167,2}{\sqrt{2}}=118,2 \mathrm{MPa}, \\
& \tau_{I I}^{\prime \prime}=0
\end{aligned}
$$

- transversal weld placed by the not fully cooperating wall of overlapping brace in connection with the chord - Eq. (3.20):

$$
\begin{aligned}
& \sigma^{\prime \prime}=\frac{P_{4}^{\prime \prime}}{a_{w} l_{4}}=\frac{20,1 \cdot 10^{3}}{3,0 \cdot 40}=167,5 \mathrm{MPa}, \\
& \sigma_{\perp}^{\prime \prime}=-\sigma^{\prime} \cos \frac{\theta_{1}}{2}=-167,5 \cdot 0,9050=-151,6 \mathrm{MPa}, \\
& \tau_{\perp}=\sigma^{\prime \prime} \sin \frac{\theta_{1^{\prime}}}{2}=167,5 \cdot 0,4253=71,2 \mathrm{MPa}, \\
& \tau_{I I}^{\prime \prime}=0
\end{aligned}
$$


- longitudinal welds placed by the walls of overlapping brace in connection with the overlapped brace - Eq. (3.23):

$\sigma^{\prime \prime}=\frac{P_{5}^{\prime \prime}}{a_{w} l_{5}}=\frac{10,1 \cdot 10^{3}}{3,0 \cdot 37,5}=89,8 \mathrm{MPa}$,

$\sigma_{\perp}^{\prime \prime}=-\frac{\sigma^{\prime \prime}}{\sqrt{2}}=-\frac{89,8}{\sqrt{2}}=-63,5 \mathrm{MPa}$,

$\tau_{\perp}^{\prime \prime}=\frac{\sigma^{\prime \prime}}{\sqrt{2}}=\frac{89,8}{\sqrt{2}}=63,5 \mathrm{MPa}$,

$\tau_{I I}^{\prime \prime}=0$,

- transversal weld placed by the wall of overlapping brace in connection with the overlapped brace ( near the connection of overlapped brace with the chord) - Eq. (3.24):

$\sigma^{\prime \prime}=\frac{P_{6}^{\prime \prime}}{a_{w} l_{6}}=\frac{10,8 \cdot 10^{3}}{3,0 \cdot 40}=90,0 \mathrm{MPa}$,

$\sigma_{\perp}^{\prime \prime}=\sigma^{\prime \prime} \cos \frac{\theta_{1}+\theta_{2}}{2}=90,0 \cdot 0,7049=63,4 \mathrm{MPa}$,

$\tau_{\perp}^{\prime \prime}=-\sigma^{\prime \prime} \sin \frac{\theta_{1}+\theta_{2}}{2}=-90,0 \cdot 0,7093=-63,8 \mathrm{MPa}$,

$\tau_{I I}^{\prime}=0$.

e) Resultant stresses in welds of the component forces:

- longitudinal welds placed by the walls of overlapped brace in connection with the chord:

$$
\begin{aligned}
& \tau_{\|}=\tau_{\|}^{\prime}+\tau_{\|}^{\prime \prime}=141,2+0=141,2 \mathrm{MPa}, \\
& \sigma_{\perp}=\sigma_{\perp}^{\prime}+\sigma_{\perp}^{\prime \prime}=0+29,6=29,6 \mathrm{MPa}, \\
& \tau_{\perp}=\tau_{\perp}^{\prime}+\tau_{\perp}^{\prime \prime}=0-29,6=-29,6 \mathrm{MPa},
\end{aligned}
$$


- transversal weld placed by the not fully cooperating wall of overlapped brace in connection with the chord:

$$
\begin{aligned}
& \tau_{\|}=\tau_{\|}^{\prime}+\tau_{\|}^{\prime \prime}=0+0=0, \\
& \sigma_{\perp}=\sigma_{\perp}^{\prime}+\sigma_{\perp}^{\prime \prime}=48,4-39,5=8,9 \mathrm{MPa}, \\
& \tau_{\perp}=\tau_{\perp}^{\prime}+\tau_{\perp}^{\prime \prime}=132,6+14,4=147,0 \mathrm{MPa},
\end{aligned}
$$

- longitudinal welds placed by the walls of overlapping brace in connection with the chord:

$$
\begin{aligned}
& \tau_{\|}=\tau_{\|}^{\prime}+\tau_{\|}^{\prime \prime}=141,1+0=141,1 \mathrm{MPa}, \\
& \sigma_{\perp}=\sigma_{\perp}^{\prime}+\sigma_{\perp}^{\prime \prime}=0-118,2=-118,2 \mathrm{MPa}, \\
& \tau_{\perp}=\tau_{\perp}^{\prime}+\tau_{\perp}^{\prime \prime}=0+118,2=118,2 \mathrm{MPa},
\end{aligned}
$$

- transversal weld placed by the not fully cooperating wall of overlapping brace in connection with the chord:

$\tau_{\|}=\tau_{\|}^{\prime}+\tau_{\|}^{\prime \prime}=0+0=0$,

$\sigma_{\perp}=\sigma_{\perp}^{\prime}+\sigma_{\perp}^{\prime \prime}=59,9-151,6=-91,7 \mathrm{MPa}$,

$\tau_{\perp}=\tau_{\perp}^{\prime}+\tau_{\perp}^{\prime \prime}=127,4+71,2=198,6 \mathrm{MPa}$,

- longitudinal welds placed by the walls of overlapping brace in connection with the overlapped brace:

$$
\begin{aligned}
& \tau_{\|}=\tau_{\|}^{\prime}+\tau_{\|}^{\prime \prime}=92,4+0=92,4 \mathrm{MPa}, \\
& \sigma_{\perp}=\sigma_{\perp}^{\prime}+\sigma_{\perp}^{\prime \prime}=0-63,5=-63,5 \mathrm{MPa}, \\
& \tau_{\perp}=\tau_{\perp}^{\prime}+\tau_{\perp}^{\prime \prime}=0+63,5=63,5 \mathrm{MPa},
\end{aligned}
$$

- transversal weld placed by the wall of overlapping brace in connection with the overlapped brace (near the connection of overlapped brace with the chord): 


$$
\begin{aligned}
& \tau_{\|}=\tau_{\|}^{\prime}+\tau_{\|}^{\prime \prime}=0+0=0 \mathrm{MPa}, \\
& \sigma_{\perp}=\sigma_{\perp}^{\prime}+\sigma_{\perp}^{\prime \prime}=-53,4+63,4=10,0 \mathrm{MPa}, \\
& \tau_{\perp}=\tau_{\perp}^{\prime}+\tau_{\perp}^{\prime \prime}=53,8-63,8=-10,0 \mathrm{MPa} .
\end{aligned}
$$

f) Checking the safety of the welds:

- longitudinal welds placed by the walls of overlapped brace in connection with the chord:

$\left[\sigma_{\perp}^{2}+3\left(\tau_{\perp}^{2}+\tau_{\|}^{2}\right)\right]^{0,5}=\left[29,6^{2}+3\left((-29,6)^{2}+141,2^{2}\right)\right]^{0,5}=251,6 \mathrm{MPa}<$

$\frac{f_{u}}{\beta_{w} \gamma_{M w}}=\frac{490}{0,9 \cdot 1,25}=435,6 \mathrm{MPa}$,

$\sigma_{\perp}=29,6 \mathrm{MPa}<\frac{0,9 \cdot 490}{1,25}=352,8 \mathrm{MPa}$,

- transversal weld placed by the not fully cooperating wall of overlapped brace in connection with the chord:

$$
\begin{aligned}
& {\left[\sigma_{\perp}^{2}+3\left(\tau_{\perp}^{2}+\tau_{\|}^{2}\right)\right]^{0,5}=\left[8,9^{2}+3\left(147,0^{2}+0^{2}\right)\right]^{0,5}=333,9 \mathrm{MPa}<} \\
& \frac{f_{u}}{\beta_{w} \gamma_{M w}}=\frac{490}{0,9 \cdot 1,25}=435,6 \mathrm{MPa}, \\
& \sigma_{\perp}=8,9 \mathrm{MPa}<\frac{0,9 \cdot 490}{1,25}=352,8 \mathrm{MPa},
\end{aligned}
$$

- longitudinal welds placed by the walls of overlapping brace in connection with the chord:

$$
\begin{aligned}
& {\left[\sigma_{\perp}^{2}+3\left(\tau_{\perp}^{2}+\tau_{\|}^{2}\right)\right]^{0,5}=\left[(-118,2)^{2}+3\left(118,2^{2}+141,1^{2}\right)\right]^{0,5}=340,0 \mathrm{MPa}<} \\
& \frac{f_{u}}{\beta_{w} \gamma_{M w}}=\frac{490}{0,9 \cdot 1,25}=435,6 \mathrm{MPa}, \\
& \sigma_{\perp}=118,2 \mathrm{MPa}<\frac{0,9 \cdot 490}{1,25}=352,8 \mathrm{MPa}
\end{aligned}
$$


- transversal weld placed by the not fully cooperating wall of overlapping brace in connection with the chord:

$\left[\sigma_{\perp}^{2}+3\left(\tau_{\perp}^{2}+\tau_{\|}^{2}\right)\right]^{0,5}=\left[(-91,7)^{2}+3\left(198,6^{2}+0\right)\right]^{0,5}=356,0 \mathrm{MPa}<$

$\frac{f_{u}}{\beta_{w} \gamma_{M w}}=\frac{490}{0,9 \cdot 1,25 .}=435,6 \mathrm{MPa}$,

$\sigma_{\perp}=91,7 \mathrm{MPa}<\frac{0,9 \cdot 490}{1,25}=352,8 \mathrm{MPa}$,

- longitudinal welds placed by the walls of overlapping brace in connection with the overlapped brace:

$\left[\sigma_{\perp}^{2}+3\left(\tau_{\perp}^{2}+\tau_{\|}^{2}\right)\right]^{0,5}=\left[(-63,5)^{2}+3\left(63,5^{2}+92,4^{2}\right)\right]^{0,5}=204,3 \mathrm{MPa}<$

$\frac{f_{u}}{\beta_{w} \gamma_{M w}}=\frac{490}{0,9 \cdot 1,25}=435,6 \mathrm{MPa}$,

$\sigma_{\perp}=63,5 \mathrm{MPa}<\frac{0,9 \cdot 490}{1,25}=352,8 \mathrm{MPa}$,

- transversal weld placed by the wall of overlapping brace in connection with the overlapped brace ( near the connection of overlapped brace with the chord):

$\left[\sigma_{\perp}^{2}+3\left(\tau_{\perp}^{2}+\tau_{\|}^{2}\right)\right]^{0,5}=\left[10,0^{2}+3\left((-10,0)^{2}+0^{2}\right)\right]^{0,5}=120,0 \mathrm{MPa}<$

$\frac{f_{u}}{\beta_{w} \gamma_{M w}}=\frac{490}{0,9 \cdot 1,25}=435,6 \mathrm{MPa}$,

$\sigma_{\perp}=10,0 \mathrm{MPa}<\frac{0,9 \cdot 490}{1,25}=352,8 \mathrm{MPa}$.

The resulting margin of safety is:

$\frac{435,6-356,0}{435,6} \cdot 100 \%=18,3 \%$. 


\section{REFERENCES}

1. Bródka J., Broniewicz M.: Steel structures made of tubes. Arkady 2001. [in Polish]

2. Bródka J., Broniewicz M.: Design of welded joints of trusses made of hollow sections. Steel Construction. 2002, No 4. [in Polish]

3. Bródka J., Broniewicz M.: Assessing of resistance of connections according to EN 1993-1-8:2006. Steel Construction. 2007, No 1. [in Polish]

4. Bródka J., KozŁowski A., Ligocki I., Łaguna J., Ślęczka L.: Design and calculating of connections and joints of steel structures. Vol. 1. Polish Technological Editor. Rzeszow 2009. [in Polish]

5. BS ISO 14346 Welding - Static design procedure for hollow section joints. Draft 2011.

6. Packer J.A., Henderson J.E.: Hollow Structural Section Connections and Truss - A Design Guide. Second Edition. Canadian Institute of Steel Construction. Toronto 1997.

7. Packer J.A., Wardenier J., Zhao X.-L., van der Vegte G.J., Kurobane Y.: Design guide for rectangular hollow section (RHS) joints under predominantly static loading. LSS Verlag. CIDECT. 2009.

8. PN-EN 1993-1-8:2006 EN 1993-1-8: Eurocode 3: Design of steel structures - Part 1-8: Design of joints.

9. Static design procedure for welded hollow section joints - Recommendations. $3^{\text {rd }}$ Edition. International Institute of Welding. Commision XV. IIW Doc. XV-1329-09.

10. Wardenier J., Packer J.A., Zhao X.-L., van der Vegte G.J.: Hollow sections in structural applications. Bouwen met Staal. Zoetemeer 2010.

11. Structural tubes of steel. Square and rectangular hollow sections. PROTUBSA

Received: 24.04 .2013

Revised: 12.11.2013 